\title{
Rapid Evidence Review of Community Engagement in The UK During The COVID-19 Pandemic: How Can Community Assets Redress Health Inequities?
}

\author{
Rabya Mughal \\ University College London \\ Linda Thomson \\ University College London \\ Norma Daykin \\ Tampere University \\ Helen Chatterjee ( $\nabla$ h.chatterjee@ucl.ac.uk) \\ University College London
}

\section{Research Article}

Keywords: Social determinants of health, community engagement, health inequity.

Posted Date: June 17th, 2021

DOI: https://doi.org/10.21203/rs.3.rs-569641/v1

License: (c) (1) This work is licensed under a Creative Commons Attribution 4.0 International License. Read Full License 


\section{Abstract \\ Background}

Community-based engagement has been crucial during the COVID-19 pandemic, fostering informal and local mutual aid between individuals, community groups, charities, community interest companies and local authorities. The current rapid evidence review examines the emergence of community-based arts, nature, music, theatre and other types of cultural engagement amongst UK communities in response to the COVID-19 pandemic. It focuses on all community engagement with a sub-focus on provisions accessed by and targeted towards vulnerable groups.

\section{Methods}

Two hundred and fifty-six resources created between February 2020 and January 2021 were reviewed. Resources were identified through Google Scholar, PubMed, Web of Science, MedRXic, PsycharXiv, and supplemented with searches for grey literature and items in the public domain. The majority reported services that had been adapted to become online, telephone based or delivered at a distance from doorsteps. Over a third of identified resources (37\%) were targeted towards socioeconomic outcomes, such as social isolation, financial difficulty or caregiver responsibilities. Over a quarter of resources (28\%) were targeted towards psychological outcomes, including individuals with mild to moderate anxiety and depression, acute mental health needs, or neurodevelopmental conditions such as Autism Spectrum Disorder. Under a fifth of resources (17\%) were targeted towards physiological outcomes, including individuals with health conditions such as dementia, chronic pain, immunological conditions, or other conditions requiring shielding. The remaining resources were open to everyone, or targeted towards other groups that did not fall into vulnerability categories such as parents or university students. Several quality assessment frameworks were used to evaluate the quality of data. Whilst a number of peer reviewed, grey literature and public domain items were identified, less than half of the identified literature met quality thresholds. The pace of the response to the pandemic may have meant robust evaluation procedures were not always in place.

\section{Conclusions}

Outreach to vulnerable audiences was generally observed via a plethora of organisations, however more robust and longitudinal evidence is needed as to the efficacy and impact of community programmes, services and activities.

\section{Background}

Holistic approaches to healthcare are now well evidenced, having been utilised by community referral specialists since the mid-1990s $(1,2)$. Community assets such as museums, libraries and third sector organisations can promote social health and wellbeing through art, nature, music or creative activities (hereby called 'community activities')(3). Participation in community activities involves aesthetic engagement, evocation of the imagination and emotion, cognitive stimulation, sensory stimulation, social interaction and physical activity - which in turn endorse positive psychological (e.g. coping and emotional strategies), physiological (e.g. lower stress hormone response), social (e.g. reduced loneliness and isolation) and behavioural outcomes (e.g. adoption of healthier behaviours and skills development) (4). Evidence suggests that such salutogenic approaches are useful in the treatment and prevention of long term conditions, can take pressure off of socialised healthcare systems, and can be effective in increasing resilience and wellbeing in individuals and communities $(1,5)$. Despite evidence of the positive impact of cultural engagement on the population in general, there remains inconsistency in the evidence for community assets as reducers of health inequity in disadvantaged, marginalised or vulnerable communities (6).

Vulnerable populations entered the COVID-19 pandemic from uneven starting points (7). Living in poverty, receiving low wages or being a member of a single parent household indicates likelihood of the highest levels of net COVID-19-related impact, whilst those living in areas of deprivation are more likely to be exposed to the Coronavirus (8). These disparities put vulnerable populations at risk of negative health outcomes which are exacerbated by already existing structural and institutional disadvantage $(7,9,10)$. For instance, those with chronic physiological or psychological health conditions are most likely to be disproportionately and adversely affected by viral load as well as socioeconomic impact (7). Those accessing hospital outpatients services and those living with chronic health conditions have experienced delays to care plans and elective treatments $(7,11)$. In addition the pandemic has changed the landscape of mental health services in the UK with the increasing need for the development of telehealth services in community care (12).

The COVID-19 pandemic resulted in an increase in community-led activity seeking to support vulnerable and shielding individuals (13). Some of these were new groups set up in response to the pandemic, whilst others were adaptations of existing services (14). Although many services have been adapted for vulnerable individuals, less is known about the efficacy of these service adaptations, their mechanisms of action or their impact on vulnerable populations.

The aim of this review was to draw together a broad summary of how community activities have been utilised during the COVID-19 pandemic. This review examines how local organisations have engaged with vulnerable and non-vulnerable groups using community activities during the COVID-19 pandemic, and how efficacy has been measured by various community organisations.

\section{Methodology}


Ethics approval was granted by the UCL Research Ethics Committee (4526.003). The datasets generated and analysed during the current study are available as supplementary material.

A rapid evidence review approach was used to scope and assess the range of resources offered; as a result a wide range of peer reviewed, grey literature and public domain resources were included, providing evidence of the variety of community engagement activities on offer during the COVID-19 pandemic (15). Inclusion criteria were: resources that outlined creative and/or nature based activities such as arts, theatre, music, sewing, social, gaming, gardening, exercise, community and other related activities (including those using museums, libraries and other cultural assets); resources that reported intervention data on the above-mentioned activities; resources that provided contextual information on the impact of the COVID-19 pandemic on vulnerable groups; and resources that provided contextual data on the psychological, physiological and socioeconomic impact of COVID-19. All resources were written in English and published between March 2020 and January 2021. Peer reviewed literature included intervention, longitudinal, random control trial, cross sectional, exploratory or narrative review data. Non-peer-reviewed resources included grey literature (comprising governmental or local authority reports, third sector reports, and study protocols) and items within the public domain (comprising of web pages, blogs, social media pages and information shared within and between communities). Exclusion criteria were: resources unrelated to COVID-19; resources targeted only at schools, children and adolescents; resources not applicable to the UK population.

A range of review methodologies were utilised to draw together a broad summary of the current evidence for the efficacy of community-based interventions on both vulnerable and non-vulnerable populations. Here 'vulnerability' is categorised by physical, psychological or socioeconomic circumstances as defined by the Office of National Statistics (16). An overview of the number of resources identified, screened and included can be seen in Figure 1.

\subsection{Search protocol}

Searches for peer reviewed literature were carried out on Google Scholar, PubMed, Web of Science, MedRXic and PsycharXiv (see Appendix for search terms; see Additional File 1 for a full list of included resources). Non peer-reviewed grey literature and public domain resources were identified using hand searching in Google, reference lists and input from the wider project team and its affiliated organisations: the Culture Health and Wellbeing Alliance (17), Arts Council England (18), Natural England (19) and UKRI March Mental Health Research Network (20). Government and statistical reports were identified via the UK government (21) and Office for National Statistics (22) websites.

\subsection{Quality Assessment}

Several quality assessment frameworks were utilised for the purposes of evaluating the quality of resources collected for this review. Examples of activities, case studies that formed part of grey literature resources, and public domain resources were quality assessed using a tool devised from the Public Health England (PHE) Arts for Health and Wellbeing evaluation framework (23). Resources that provided more than 10 out of 15 relevant PHE Arts for Health and Wellbeing evaluation criteria met this review's quality assurance threshold. Grey literature reports were evaluated using AACODS (authority, accuracy, coverage, objectivity, date and significance) critical appraisal (24). Grey literature that scored in the top third (>22 out of 34) of the AACODS criteria met this review's quality assurance threshold. Peer reviewed literature was evaluated using AMSTAR (25) for reviews and Cochrane Quality Appraisal (26) for intervention, cross sectional or regression data. Literature was strategically sampled and checked by all four authors.

\subsection{Data classification}

See Table 1 for data classification. Data were extracted from resources using the Population, Intervention, Control, Outcome (PICO) model for clinical evaluation (27). The target population was identified according to the ONS categories of vulnerability (16). These are: 'Psychological Vulnerability' including acute mental health needs, neurodevelopmental or intellectual disability, or eating, anxiety or mood disorders (Population Area A); 'Physical Vulnerability' involving underlying health conditions, chronic pain, respiratory problems etc., extending to Dementia which is classified here as a physiological condition (Population Area B); and 'Socioeconomic Vulnerability' such as situational poverty, deprivation, rural isolation, low income or protected characteristics such as ethnicity which are associated with inequitable outcomes (Population Area C) (9). Additional categories of data were used to augment the PICO classifications to draw out particular aspects of the data such as geographic location, types of research or evaluation methods employed, duration and length of intervention. All data can be found in Supplementary Information (Additional File 1).

A considerable amount of contextual literature that did not report interventions or activities was identified within the search. This was incorporated into a narrative review of the impact of the pandemic and the range of responses focused on mental and physical wellbeing. A summary of peer-reviewed and grey, public domain literature (e.g., websites, public information or social media resources) assessed how community activities addressed needs within the three vulnerability categories.

\section{Table 1: Data Classification}


Data Peer reviewed literature (Contextual literature, Intervention Studies; Review of Interventions)

Classification Grey Literature (Evaluation Reports; NGO reports; Government reports; Charity reports)

Public Domain (Charity Webpage; Mutual aid resources; Community outreach; Commercial; Social media posts)

\begin{tabular}{|c|c|c|}
\hline & $\begin{array}{l}\text { Data } \\
\text { Classification }\end{array}$ & $\begin{array}{l}\text { Peer reviewed literature (Contextual literature, Intervention Studies; Review of Interventions) } \\
\text { Grey Literature (Evaluation Reports; NGO reports; Government reports; Charity reports) } \\
\text { Public Domain (Charity Webpage; Mutual aid resources; Community outreach; Commercial; Social media posts) }\end{array}$ \\
\hline & $\begin{array}{l}\text { Type of } \\
\text { resource }\end{array}$ & $\begin{array}{l}\text { E.g. charity project, } \mathrm{CIC} \text { project, cultural asset case study, example of activity, online resource, project case study, RCT, } \\
\text { cross sectional study, longitudinal study, population analysis, service evaluation, thought piece, unpublished study. }\end{array}$ \\
\hline \multirow[t]{3}{*}{ Population } & $\begin{array}{l}\text { Vulnerability/ } \\
\text { RER theme }\end{array}$ & Psychological/ Socioeconomic/ Physiological/ Other. \\
\hline & Subtheme & $\begin{array}{l}\text { E.g. Addiction, caregiving, chronic pain, coping, deprivation, digital poverty, eating disorder, elderly, everyone in the } \\
\text { community, low income, resilience, shielding. }\end{array}$ \\
\hline & $\begin{array}{l}\text { Target } \\
\text { Population }\end{array}$ & $\begin{array}{l}\text { E.g. All/ everyone in the community, adults with mental health issues, careleavers, dance professionals, disabled } \\
\text { artists, hospital patients, people using foodbanks, prison staff, people experiencing chronic pain, members of local } \\
\text { choirs }\end{array}$ \\
\hline \multirow[t]{8}{*}{ Intervention } & $\begin{array}{l}\text { Type of } \\
\text { intervention }\end{array}$ & $\begin{array}{l}\text { E.g. Animals, creative, cooking, cultural, gaming, gardening, music, poetry, protest, movement, dance, } \\
\text { sewing/embroidery, museums }\end{array}$ \\
\hline & $\begin{array}{l}\text { Method of } \\
\text { delivery }\end{array}$ & E.g. online, posted, door to door, over Zoom. \\
\hline & Exposure & E.g. One hour \\
\hline & Frequency & E.g. Once a week \\
\hline & Duration & E.g. Over the period of three months; over the duration of lockdown \\
\hline & $\begin{array}{l}\text { Quality } \\
\text { assurance }\end{array}$ & E.g. Therapist led, mental health professional led, professional musician led, professional artist led. \\
\hline & $\begin{array}{l}\text { Cost to } \\
\text { Participant }\end{array}$ & E.g. No cost to participant, membership fee of $£ 5$ per month \\
\hline & $\begin{array}{l}\text { Geographical } \\
\text { location }\end{array}$ & $\begin{array}{l}\text { UK wide, Northern Ireland, Scotland, NE England, NW England, Central England, Wales. Midlands, South East England, } \\
\text { South West England, Greater London, International (but applicable to UK population) }\end{array}$ \\
\hline Control & $\begin{array}{l}\text { Was a control } \\
\text { group used? }\end{array}$ & No control group/ Control group (n)/ Comparison data \\
\hline \multirow[t]{3}{*}{ Outcome } & $\begin{array}{l}\text { Aims/ } \\
\text { objectives }\end{array}$ & Eg. Reach out to BAME audience, combatting isolation, improve health and wellbeing, improve access to service \\
\hline & $\begin{array}{l}\text { Evaluation } \\
\text { methodology }\end{array}$ & $\begin{array}{l}\text { E.g. anecdotal, feedback forms, evaluation questionnaires, validated measurements (e.g. WEMWBS), formal } \\
\text { evaluation in partnership with a university, statistical evaluation, no evaluation used }\end{array}$ \\
\hline & Outputs & g. events, exhibitions, online gallery, website, number of sessions. Some comlpeted, some intended. \\
\hline
\end{tabular}

\section{Results}

This review included a total of 256 resources. Fifty one of these (20 per cent) were peer reviewed studies, 72 (28 per cent) were grey literature, and 133 (52 per cent) were resources found in the public domain. Peer reviewed contextual data included literature on the impact of the pandemic on various vulnerable populations, for example increases in anxiety symptomology as government lockdowns progressed, coping mechanisms utilised by elderly or isolated individuals, or barriers to participation in outdoor activities for people with chronic health conditions. Intervention studies and review of interventions outlined the efficacy of community activity interventions during the COVID period. Grey literature also provided contextual information such as government and think tank reports on economic or policy impact, and additionally provided information from charities and community organisations on community activities. Public domain resources included a range of community activities providing an overview of the breadth of projects, schemes and community engagement occurring during the pandemic. Hereon public domain resources identified by this review are marked with ' $\mathrm{R}$ ' and correspond to Supplementary Table 1. Peer reviewed and grey literature resources are referenced with the same number in both in the supplementary table and within the reference list. 


\begin{tabular}{|c|c|c|c|c|c|c|}
\hline & $\begin{array}{l}\text { Population Area A - } \\
\text { Psychological } \\
\text { (\% total) }\end{array}$ & $\begin{array}{l}\text { Population Area B - } \\
\text { Physiological (\% total) }\end{array}$ & $\begin{array}{l}\text { Population Area } \\
\text { C-Social } \\
\text { (\% total) }\end{array}$ & $\begin{array}{l}\text { Other Populations } \\
\text { (\% total) }\end{array}$ & $\begin{array}{l}\text { Open } \\
\text { to All } \\
\text { (\% } \\
\text { total) }\end{array}$ & $\begin{array}{l}\text { Total } \\
\text { (\% of } \\
\text { total) }\end{array}$ \\
\hline $\begin{array}{l}\text { Peer reviewed } \\
\text { (contextual literature) }\end{array}$ & 23 & 11 & 1 & 1 & 4 & $\begin{array}{l}40 \\
(16 \%)\end{array}$ \\
\hline $\begin{array}{l}\text { Peer reviewed } \\
\text { (intervention study) }\end{array}$ & 4 & 4 & 0 & 0 & 0 & $\begin{array}{l}8 \\
(0.03 \%)\end{array}$ \\
\hline Peer reviewed (reviews) & 3 & 0 & 0 & 0 & 0 & $\begin{array}{l}3 \\
(0.01 \%)\end{array}$ \\
\hline Grey literature & 26 & 19 & 23 & 0 & 4 & $\begin{array}{l}72 \\
(28 \%)\end{array}$ \\
\hline Public domain & 22 & 9 & 71 & 6 & 25 & $\begin{array}{l}133 \\
(52 \%)\end{array}$ \\
\hline Total & $\begin{array}{l}78 \\
(30.4 \%)\end{array}$ & $\begin{array}{l}43 \\
(16.8 \%)\end{array}$ & $\begin{array}{l}95 \\
(37.1 \%)\end{array}$ & $\begin{array}{l}7 \\
(0.03 \%)\end{array}$ & $\begin{array}{l}33 \\
(12.9 \%)\end{array}$ & 256 \\
\hline
\end{tabular}

\subsection{Contextual Literature Review}

Sixteen per cent of resources identified were classified as 'contextual', i.e. peer reviewed data that provided an overview of the psychological, physical and, or, social impact of the COVID-19 pandemic. Within Population Area A (Psychological Vulnerabilities) contextual peer reviewed data reported population trends and regression data on coping mechanisms, poor mental health, or increased symptomology in established psychiatric disorders. This body of data revealed growing concerns around the psychological impact of the pandemic in the UK, a country in which increasing case rates of mental health conditions have been noted over the past several years (28). There additionally appeared to be an abundance of data reporting the increased need for mental health services during the pandemic (28-39). Pierce et al. (28) for example reported that lockdown-related trigger mechanisms such as entrapment and loneliness were associated with higher rates of depression, self-harm, suicide and overall poorer mental health during the pandemic. These rates may have been due to lockdown lifestyle adaptations such as increased screen time and decreased exercise impacting sleep, increased stress, and decreased wellbeing and physical health (40-43). In comparison to previous years' trends, the Office for National Statistics General Health Questionnaire data showed an 8.1 per cent decrease in mental wellbeing between March-June 2020 (44). Office for National Statistics longitudinal data showed a significant decrease in mental wellbeing and affect alongside an increase in distress patterns particularly amongst those in lower socioeconomic brackets, young people, and mothers of preschool children, for whom the pandemic was associated with heavier socioeconomic impact (16). Several non-governmental organisations additionally reported psychological effects of lockdowns, as well as coping strategies. The Wellcome Trust for example captured how arts and creativity, community relationships, philosophy, nature, green spaces, gaming, volunteering, activism and learning were utilised as coping mechanisms for increased anxiety $(45,46)$. The Royal Horticultural Society, National Trust, Royal Society for the Protection of Birds, 56 Degree Insight and Thrive reported increases in membership interest, alongside increased interest in nature and outdoor activities during the pandemic (47-51). The Crafts Council noted in its annual report the meditative benefits and increase in craft making during the pandemic (52). Meanwhile those with established psychiatric disorders, learning disabilities, neurodevelopmental conditions such as Autism Spectrum Disorder, or ongoing treatment for conditions such as eating disorders, experienced a severe reduction in access to points of statutory contact (53-55). Services designed to implement salutogenic approaches in the community were reported to be overstretched during the pandemic, having been fragile and at capacity beforehand $(56,57)$. Such service gaps may be addressed through a participatory approach $(58)$ or digital interventions $(59,60)$.

Categorised within Population Area B (Physiological Vulnerabilities), a considerable amount of contextual literature was found regarding the importance of regular physical exercise in combatting COVID-19, as well as the effect of comorbidity on case rates. Physical activity was reported to be useful in combating diseases associated with increased inflammation, including metabolic and infectious diseases acute respiratory infections, whilst sedentary lifestyles impact negatively on general health status and mental health outcomes (61-64). COVID-19 is a multi-organ disease in which physical activity and inflammation status is a mediator of symptom severity and cross-organ communication. Adverse viral effects are regulated by skeletal muscle contraction, immune system responses and effects on adipose tissue (63). Higher body mass index (BMI) is associated with higher disease impact, alongside lower mental health, lower physical activity levels and higher overeating during the pandemic (65), whilst reduction in inflammation status allowed effective counteracting of COVID-19 infection (63). Thus public health messages around staying active were crucial during the pandemic.

\subsection{Community Activities within Population Area A: Psychological Vulnerability}

A total of 78 identified resources, comprising peer reviewed and grey literature, and public domain resources, addressed psychological vulnerability (Table 2). Resources within Population Area A were comprised of interventions and activities for individuals with mental health needs as well as activities and interventions targeting all groups with general mental health or wellbeing as an intended outcome. The main groups identified or targeted were individuals experiencing addiction, anxiety, cognitive impairment, depression, eating disorders, adults with learning difficulties, or Autism Spectrum Disorder. 
In response to the issues highlighted by the pandemic, numerous community organisations adapted services to reach out to people with psychological vulnerabilities. At the beginning of the pandemic, community organisations and charities adapted their websites to contain online resources to navigate users towards shopping, test and trace, and health services (R68, R69, R72, R73, R75). Others offered information on what to do in the event of a mental health crisis during lockdown (R3) or, in the case of adults with learning disabilities, user friendly and accessible factsheets outlining the meaning of COVID-19 'lockdown', the need to wash hands and socially distance (R64, R65). The majority $(66 \%)$ of community organisations moved their offers online. Several used platforms such as Zoom to deliver arts and craft or painting tutorials (R10, R48, R160), photography and mindfulness courses (R146), interpretative dance (R10) or choir practice (66) with the intent of alleviating psychological distress arising from addiction (R24, R48, R73), head injury (R18), palliative care (R18), caregiver burden (R48, R67, R72), postnatal depression (R52) or general wellbeing (R56, R57, R59, R72) and mental health (R1, $\mathrm{R} 10, \mathrm{R} 18, \mathrm{R} 29, \mathrm{R} 48, \mathrm{R} 49)$ as intended outcomes. Some community organisations sent 'creative care packages' through the post such as papercraft activity packs containing pencils, paint, coloured paper, glue, stickers and activity work books (R121, R132, R160, R159) as well as music and singing at home activity packs (R132). Three community organisations, Beaney House of Art and Knowledge, Look Again South West, and Suffolk Art Link, hosted online art tutorials, sent out art packs and presented their users with the opportunity to exhibit artwork in online galleries (R4, R18, R57). One private sector organisation uploaded pictures and videos of serene railway journeys from around the world in order to promote mindfulness and calm (R127).

Of the 31 community activities identified targeting people with mental health difficulties, three evaluated their activities using validated outcome measurements (R18, R29, R70). Tees, Esk and Wear Valley NHS Trust reported a music and wellbeing programme for NHS staff using validated wellbeing questionnaires alongside regression analysis to measure impact (R29), whilst others such as Look Again and Performance Medicine partnered with universities to measure impact (R18, R70). The other 28 community activities either reported outcomes, participant feedback, challenges and successes, survey results, or output including numbers of participants, phone and video calls as measures of impact, but did not employ validated outcome measures. Six reported more generic outcomes with two stating that their outcomes "promote wellbeing" and "support mental health" (R48, R49) and others suggesting that their offer aimed to promote "practical ways to stay connected" (R69), "combat loneliness" (R72), support the 'Six Ways to Wellbeing' framework (R4) or "reduce anxiety and increase resilience" (R34). Four used feedback quotes from participants (e.g. "I found the process of drawing and painting both cathartic and healing at the most difficult time of my life"; R30, R52, R56, R59); four reported challenges and successes (e.g. "unable to engage with digital content", "offline activity is more labour intensive"; R17, R29, R48, R49); and one community group used their own survey to measure impact (R1). Others reported their outputs as a measure of impact (e.g. "we created a new website"; R48) whilst others counted participant numbers and retention (R18, R52, R56) or increased use of phone calls and zoom meetings (R57).

Peer reviewed data identified by the review consistently reported increased wellbeing in relation to community activities. Pierce et al (28) reported that individuals with higher levels of social support were more likely to participate in community volunteering whilst those with diagnosed mental health conditions were more likely to engage in social action volunteering, in contrast to volunteering trends during non-emergency periods (29). "Happiness" and "gratitude" were significantly associated with nature walks and hiking (67) whilst one meta-analysis (54) reported that self-guided interventions such as Cognitive Behavioural Therapy, mindfulness and acceptance therapy used alongside music and physical exercise, helped with stress and coping behaviour (54). Meanwhile cooking, decorating, diary writing and researching were related to positive emotions (67) whilst amount of gaming time, contrary to popular belief, was slightly but statistically significantly correlated $\left(\beta=0.31 ; R^{2}=0.15\right)$ with wellbeing (68). Volunteering (56), showing kindness (69), gaming (70), foraging (71), being in nature (72,73), listening to music (74), exercising (75), sewing (76) and engaging in arts and crafts (77) were shown to positively impact wellbeing during the pandemic.

Further peer reviewed evidence suggested that interaction with nature increased during lockdown with 60-72 per cent of one large scale survey of 703 UK adults reporting an increased desire to spend time amongst nature, with 94 per cent of this sample recording that they had heard more birdsong, with benefits of noticing nature described as: "mindful”, "liberated", "togetherness" or "self-worth" (51, p.9)

Table 3 outlines the major and minor themes organised by PICO for Population Area A.

Table 3: Major and Minor themes organised by PICO for Population Area A

\begin{tabular}{|c|c|c|c|c|}
\hline & $\begin{array}{l}\text { Population } \\
\text { (\% resources) }\end{array}$ & $\begin{array}{l}\text { Intervention } \\
\text { (\% resources) }\end{array}$ & $\begin{array}{l}\text { Control } \\
\text { (\% } \\
\text { resources) }\end{array}$ & $\begin{array}{l}\text { Outcome } \\
\text { (\% resources) }\end{array}$ \\
\hline $\begin{array}{l}\text { Major } \\
\text { theme }\end{array}$ & $\begin{array}{l}\text { All Individuals with general mental health or } \\
\text { wellbeing as an outcome } \\
(56 \%)\end{array}$ & $\begin{array}{l}\text { Art/ Creativity } \\
(27 \%)\end{array}$ & $\begin{array}{l}\text { No } \\
\text { Controls } \\
(100 \%)\end{array}$ & $\begin{array}{l}\text { Wellbeing } \\
(28 \%)\end{array}$ \\
\hline $\begin{array}{l}\text { Minor } \\
\text { themes }\end{array}$ & $\begin{array}{l}\text { Learning difficulties (11\%), Eating disorders (5\%), } \\
\text { Anxiety }(4 \%) \text {, Other (24\%). }\end{array}$ & $\begin{array}{l}\text { Nature }(13 \%) \text {, Gaming (3\%), Gardening } \\
(3 \%) \text {, Other (54\%). }\end{array}$ & & $\begin{array}{l}\text { General mental health } \\
(25 \%), \text { Other }(47 \%) \text {. }\end{array}$ \\
\hline
\end{tabular}

\subsection{Community Activities within Population Area B: Physical Vulnerability}

Seventeen percent of all resources identified were categorised into Population area B: Physical Vulnerability. The largest number of these were aimed towards individuals with Dementia; these are reported separately below. The remaining resources were targeted towards participants with physical health conditions and focused on individuals who were shielding, with immunocompromising conditions, or living with chronic pain. Other resources were aimed at a wider audience but focused on different physical interventions such as singing for lung health, exercise, activity or dance.

Page 6/15 
The pandemic increased public park visits and highlighted the need for more green spaces to be integrated into the urban infrastructure (79). Operational changes and upheaval to exercise referral schemes impacted mental health particularly due to pandemic related restrictions and a lack of available exercise $(61,80)$. According to a cross-cultural comparison study (81), lower levels of exercise were associated with poorer mental health outcomes in the UK, Ireland, New Zealand and Australia, with the younger age category of 18-29 year-olds showing the largest decrease in physical activity out of any of the measured demographics (61). Similarly, a longitudinal study with almost 6,000 participants (82) found a population-wide 63 per cent decrease in physical activity during the pandemic, with high income earners increasing activity levels, and younger age groups showing the highest reduction in physical activity (82). Sport England reported "unprecedented" drops in physical activity amongst its survey of 2000 UK adults (83) which coincides with increased levels of over-eating behaviours (65). Conversely, younger people were most likely to engage in more intense physical exercise with confounding factors being access to outdoor space, higher income and being female. Those with obesity, hypertension, lung disease and living alone appeared less likely to change their physical activity habits (80).

The literature reported several physical exercise, outdoor activity, dance and movement-related activities that were established during the pandemic that were aimed both at individuals who were shielding due to underlying health conditions, and the community as a whole. Online yoga classes for instance had positive effects on pain intensity, anxiety and depression (84), whilst interpretative dance practice generated feelings of collectiveness and cultural togetherness (85), although the challenges of teaching and limited proximity raised concerns around the equity of access. There were mixed reports on the impact of arts-based activities on physical health. For instance singing during the pandemic helped improve lung health, depression and confidence but not other psychological or health measures including physical function, energy, emotional wellbeing, pain, social function, general health or health change over the past year (86). In-person singing additionally was found to increase the aerosol risk of transmitting COVID-19 (87).

Within the community, grey literature and public domain resources described various arts-based interventions. Escape Arts (R12) and University of Cambridge Museums (R58) sent out creative art packs, physical resources and family activity ideas to parents who were shielding and parents of children with terminal illness. Several community organisations organised live music including classical concerts and choirs (R116, R172), online exhibitions for shielding individuals to display their work (R4, 13), art on windows (R19), at home museum collections and crafts (R23), food creativity and world culture (R27) and drama, entertainment and doorstep theatre (R28) for individuals who were shielding.

\subsubsection{Dementia}

Fifteen of the 39 items identified by the review pertaining to individuals with physical health conditions were targeted at individuals with dementia and their caregivers, owing presumably to the impact of the pandemic on this population. A national survey reported that the public health restrictions reduced day to day access to statutory social support services, social activities in the community such as choirs, reading groups and befriending services, and were negatively associated with the mental health and wellbeing of older people, people with dementia and their caregivers (88).

Alzheimer's UK published online resources for people with dementia and their caregivers, outlining available support within hospitals and care homes as well as general information on Coronavirus and its effect on individuals with dementia (R71). Similarly, the Alzheimer's Society published positive mental health resources for individuals with dementia and their carers as well as advice on shopping, leaving home and safeguarding; music and reminiscence activities were published on their website with large fonts and an accessible user interface (R144). Reminiscence resources were also published by the BBC and the Museum of London in 2020 providing visual prompts for individuals with dementia to remember and reflect on the past by scrolling through archival film footage of the twentieth century (R21, R149).

There is evidence to suggest wellbeing can be enhanced through community-based arts activities, which can create feelings of social connections, happiness and rejuvenation (89). Community organisations targeted at individuals with dementia sent out visual art, arts and crafts creativity packs and regular telephone check ins (R21, R22, R38, R45, R47) whilst others such as Acto Dementia used in-community focus groups to test and recommend art, gardening, sports or boardgame touchscreen apps to aid with activity setting during self-isolation (R145). Museum and social prescribing resources were also made available either through online weekly meetups or signposting to remote access art events aimed for people with dementia (R147, R51). Three community organisations identified offered online weekly workshops: the Garden Museum offered 'Clay for Dementia', an eight week pottery class (R50); Aspex offered a weekly art workshop over zoom (R43); and Lost in Art (R47) has been delivering visual arts based activities during the pandemic. Table 4 outlines the major and minor themes organised by PICO for Population Area B.

Table 4: Major and Minor themes organised by PICO for Population Area B

\begin{tabular}{|c|c|c|c|c|}
\hline & Population & Intervention & Control & Outcome \\
\hline & (\% resources) & (\% resources) & (\% resources) & (\% resources) \\
\hline $\begin{array}{l}\text { Major } \\
\text { Theme }\end{array}$ & Dementia (35\%) & Creative/ Art (51\%) & $\begin{array}{l}\text { No control } \\
(91 \%)\end{array}$ & Improve health and wellbeing (58\%) \\
\hline $\begin{array}{l}\text { Minor } \\
\text { Themes }\end{array}$ & $\begin{array}{l}\text { Shielding }(16 \%) \text {, Physical activity }(12 \%) \text {, } \\
\text { Other (37\%) }\end{array}$ & $\begin{array}{l}\text { Music }(14 \%) \text {, exercise }(14 \%) \text {, } \\
\text { Other }(21 \%)\end{array}$ & $\begin{array}{l}\text { Control RCT } \\
(\mathrm{n}=4 ; 9 \%)\end{array}$ & $\begin{array}{l}\text { Reduce isolation and loneliness (32\%), } \\
\text { Other (10\%). }\end{array}$ \\
\hline
\end{tabular}

\subsection{Community Activities within Population Area C: Socioeconomic vulnerabilities}


This review sought to assess the extent to which health inequity was addressed by community initiatives. The majority of the literature found was based on community initiatives or interventions around social isolation, loneliness and community togetherness but only $16.5 \%$ (17 out of 103 ) of articles were aimed specifically at individuals in deprivation categories. Higher rates of covid-related impact amongst individuals in the more deprived categories highlights social and regional health inequity and a social gradient in health outcomes (7) whilst policy and societal responses will largely determine future health, wellbeing and economic outcomes for individuals in these deprived and protected categories (9). Arts on prescription and leisure initiatives can address health inequity $(90,91)$ but there is a long way to go particularly given that engagement in arts activities (as well as the availability of such resources) is limited and influenced by social and geographic factors (33).

The most obvious starting point for this hand search was found within the resources aimed at ameliorating financial worries for low paid workers, small business owners and third sector organisations. Financial and business advice for arts professionals were found (R86) alongside many microsites outlining aid to recovery, help with universal credit, "staying well, supported and creative" during the pandemic, as well as resources for networking, online collaboration, contingency planning or mental health advice for students and young renting professionals on low incomes (R77, R79, R80, R81-R83, R87, R88). The National Council for Voluntary Organisations offered business advice, identifying risk and resources on managing budgeting and staffing (R85) and the National Endowment for Science, Technology and the Arts published a repository of advice and funding avenues for small businesses (R84).

The majority of arts based community resources identified (58 out of 103) were targeted towards isolated and lonely individuals. Creative and arts-based interventions included initiatives such as communal art, community notice boards, chalk murals, online arts and crafts clubs, participatory arts projects (R89-R93, R96-R98, R100-R104, R110, R111, R151), online workshops, digital art creative community for carers, at home DIY art kits, block printing, art tutorials, stand-up comedy, reading groups, heritage from home and art from home resources (R3, R25, R39, R105, R110, R117, R118, R119, R120, R121, R125, R128, R164). Others provided singing workshops, neighbourhood singalongs, sing for better breathing workshops (R95, R112, R139, R140). A number of music related provisions were also offered for isolated individuals such as back garden gigs, online jamming sessions, dance live streams and a BBC orchestra for isolated people (R60, R99, R124, R130, R132). Nature activities for isolated individuals focussed on foraging, outdoor hiking ideas and wildlife webcams (R36, R42, R94, R135, R142, R143).

Seventeen resources were identified that were targeted towards individuals experiencing deprivation, themed into: abuse, asset poor, care leavers, families in chronic crisis, digital poverty. For those experiencing abuse, Creative Learning Guild sent out arts based creative care packages which were praised by social workers as promoting family togetherness and reducing stress (R9). Two organisations, the Wildlife Trust and Outdoors for All, set up webcams in natural environments to enable people in urban areas to access green spaces and nature digitally, however evaluation and feedback was not available for either activity (R36, R42). Collective Encounters published a report on the positive role of participatory theatre on social change, but that challenges remain in reaching vulnerable audiences such as those experiencing situational and digital poverty for whom online activities are difficult to engage in (92). During the pandemic a number of novel partnerships within the community arose between cultural organisations and local risk registers. 'No-one in Holbeck and Beeston Goes Hungry' for example was a community scheme in Leeds in which a food bank and theatre were established within a working men's club (R179), whilst another organisation, the Old Courts Arts Centre in Wigan, used their event and management logistics, existing technology and furloughed workers to turn the arts centre into a food bank warehouse and distribution centre for the community (R182). Another local authority organisation, FEAST, utilised out of work artists to work within deprived communities in Cornwall (R181). Create is a national organisation that reached out to young carers and their families during the pandemic through photography, dance, drama and music workshops run by artists over four weeks of lockdown (R8) and Coram Letters in Lockdown provided writing workshops for young carers and their families (R7). Both Create and Coram used novel (unnamed) evaluation questionnaires and feedback quotes to evaluate their services. Everyone Connected and the Arts Council offered support for communities experiencing digital poverty through access to accurate health information online, allowing interaction with medical support, using essential services and allowing individuals to stay locally connected (R61, R62, R157) and Arts council through developing digital skills, networking and digital training. Resources for prison staff and voluntary organisations working with people in the criminal justice system both within prison and in the community (R74).

Table 5 outlines the major and minor themes organised by PICO for Population Area C.

Table 5: Major and Minor themes organised by PICO for Population Area C

\begin{tabular}{|c|c|c|c|c|}
\hline & Population & Intervention & Control & Outcome \\
\hline & (\% resources) & (\% resources) & $\begin{array}{l}(\% \\
\text { resources })\end{array}$ & (\% resources) \\
\hline $\begin{array}{l}\text { Major } \\
\text { Theme }\end{array}$ & Isolated (53\%) & Creative/ Art (73\%) & No control & $\begin{array}{l}\text { Improve community cohesion } \\
(56 \%)\end{array}$ \\
\hline $\begin{array}{l}\text { Minor } \\
\text { Themes }\end{array}$ & $\begin{array}{l}\text { Deprivation (15\%), Low income (10\%), Older (6\%), } \\
\text { Other (16\%) }\end{array}$ & $\begin{array}{l}\text { Music (12\%), Nature (4\%) Other } \\
(11 \%)\end{array}$ & - & Isolation (8\%), Other (36\%). \\
\hline
\end{tabular}

\subsection{Quality Assessment of Literature}

Due to the varied nature of the reviewed literature, several quality assessment frameworks were used to evaluate quality. Examples of activities, case studies that formed part of grey literature resources, and public domain resources were quality assessed using the Arts for Health and Wellbeing evaluation framework (23). Broadly speaking the assessment fell into two categories - essential information (for example, aims and objectives, commissioner and funding sources, timescales, exposure, type of intervention, quality assurance) and evaluation details (evaluation aims, type of evaluation, evaluation 
design). Considered together, this information can paint a picture of the impact and need for the intervention. Peer reviewed data was quality assessed using Cochrane and AMSTAR evaluation methods, whilst grey literature was measured using AACODS critical appraisal tool. In conducting quality assessments it may be possible to evaluate whether efficacy claims could be validated with a robust methodological framework. As Table 6 shows, whilst a number of peer reviewed and grey literature articles were identified, less than half of the identified literature met quality thresholds.

Table 6: Quality appraisal of resources

\begin{tabular}{ll}
\hline Appraisal tool & Resources $(\boldsymbol{n})$ \\
\hline Cochrane (total applicable) & $\mathbf{5 0}$ \\
\hline Cochrane Bronze & 45 \\
\hline Cochrane Silver & 5 \\
\hline Cochrane Gold & 0 \\
\hline AMSTAR (total applicable) & $\mathbf{3}$ \\
\hline AMSTAR High & 0 \\
\hline AMSTAR Moderate & 1 \\
\hline AMSTAR Low & 0 \\
\hline AMSTAR Critically Low & 2 \\
\hline PHE (total applicable) & 181 \\
\hline PHE $>10$ & 54 \\
\hline AACODS (total applicable) & 22 \\
\hline AACODS > 22/34 & 11 \\
\hline
\end{tabular}

\section{Limitations}

Several limitations to this review should be considered. Firstly, it is systematised but not systematic due to the diversity of resources, which span peerreviewed, non-peer reviewed and public domain information. It was beyond the scope of this review to capture all community activities during the COVID19 pandemic. It therefore offers a broad sample of the available evidence. Within the included studies, several instances of reporter, geographical or socioeconomic bias were identified. Whilst this is a wider limitation of the field of study, it must be noted here that more information on accuracy and generalisability of studies should be taken into consideration. Unlike other reviews, the present study includes both interventions and non-interventions, whilst the contextual information provides a picture of the impact of the pandemic as well as the emergent and urgent concerns that ought to be addressed by community interventions.

\section{Summary Of Findings}

This review identified 256 resources comprising peer reviewed articles, grey literature and information within the public domain. Excluding contextual data, the review found 217 peer reviewed, grey literature and public domain items. Peer reviewed data included interventions, randomised controlled trials and reviews of interventions focusing on community engagement supporting health outcomes. Grey literature resources included non-peer reviewed reports and case studies conducted by charities, governmental departments and university research departments. Resources in the public domain provided examples of community engagement such as mutual aid groups and online community activities. The review identified a large number of arts, creative, crafts, textiles and embroidery, gardening and nature, music, theatre, exercise, board-gaming and social activities designed with the intention of ameliorating negative social health outcomes. The majority of resources were aimed either at wellbeing and positive mental health, or social isolation and loneliness. Whilst it is clear that an abundance of activity materialised during the pandemic, its impact and efficacy is less clear. Most peer-reviewed literature fell within the Cochrane 'Bronze' category with 11 per cent attaining 'Silver' and none attaining 'Gold'. Of the three articles assessed using AMSTAR, two were 'Critically Low' and one was 'Moderate'. Only a third of grey literature and public domain resources met the PHE threshold for quality whilst half met the quality criteria for grey literature. Within the case study, grey, and public domain literature, articles were more likely to be of better quality if they had completed or published evaluation methods - even if those methods were not established or validated.

\section{Discussion}

The aim of this review was to understand the scope, efficacy and nature of community-based interventions for vulnerable and non-vulnerable populations during the pandemic. A large number of community initiatives were found seeking to mitigate social, physical and psychological vulnerabilities during the pandemic. A minority provided effective reach to vulnerable populations using established evaluation methods to validate their data however there is need for more high-quality literature on the role of community activities in the mitigation of vulnerabilities.

Salutogenic approaches are strongly supported by the evidence base, particularly in regard to their positive psychological, psychological, social and behavioural outcomes $(1,4,5)$. Whilst a large number of community initiatives were identified within the present search, there was a lack of clarity regarding 
the impact of initiatives with many providing anecdotal evidence only, with few employing validated wellbeing measures. Consequently, this review found a lack of validated efficacy and impact data regarding the benefits of salutogenic approaches on vulnerable individuals during the pandemic. Within each resource identified, the authors firstly assessed whether evaluation methods were reported on at all, and secondly assessed the validation of the evaluation methods. In some instances it was not always clear whether an organisation completed an internal evaluation, or perhaps whether there was need for one when considering micro-organisations such as mutual aid groups. Future research in this area should consider the value of different types of evaluation methods, particularly those that are straightforward for organisations to report. The PHE Arts for Health and Wellbeing Evaluation Framework (23) for example can be used to validate qualitative feedback such as reporting on challenges and successes of projects, and participant feedback, or reporting whether quality assurance standards were met (for example, within the design and professional delivery of the activity). Such measures when used by community organisations can contribute valuable evaluation data and contribute to the measurement of impact and efficacy. Furthermore, evidence of intervention success was also lacking within the identified literature. Only eleven of the peer reviewed resources were intervention studies assessing the health impact of community engagement, all of which reported on anxiety, coping, wellbeing, Dementia symptomology and chronic pain. None assessed socioeconomic vulnerabilities.

Overwhelmingly, peer-reviewed literature reported positive impact of community engagement on mental health and wellbeing, however several limitations were found, primarily with generalisability to the overall population and internal bias relating to reliability of data. In some instances the sample participants were weighted in age, socioeconomic status and digital literacy and not representative of the general population. One study conducted by Loynes (78) for example reported that $94 \%$ of participants had heard more birdsong during the first lockdown. A potential sample bias in this study was that the online, older age and higher socioeconomic status-weighted sample was not representative of the general population. Those living in densely populated areas, in high rise buildings, or with less access to outdoor space may have differing experience of (or access to) nature which was not reported in the study. This is particularly important when assessing items which are dependent on demographic data such as community engagement. An article by Johannes, Vuorre \& Przybylski (68) as another example reported higher levels of mental wellbeing was associated with longer video gameplay, however the research, which was commissioned by EA Games and Nintedo, described only focussed on two 'light touch' games aimed at children were analysed within their sample of adults and so were not representative of gaming normally associated with negative outcomes (68).

From the content of the data that were collected it may be the case that salutogenic approaches occur alongside and reinforce traditional community and public health approaches rather than replace them. For instance, charities working with adults with learning difficulties (R64- R68, R72) extensively disseminated public health information regarding the new virus, washing hands, social distancing, how to get help if an individual feels unwell, etc. alongside coping strategies, meditation and other such holistic advice. The dissemination of public health information regarding the new virus was essential information for this community as were holistic interventions targeting mindfulness and coping mechanisms.

The impact of community engagement on socioeconomically vulnerable populations in mitigating pandemic impacts, remains less clear. It is already known that lower levels of wellbeing and socioeconomic positions are individually associated with lower levels of cultural engagement (33). Fancourt \& Baxter (33) explain this discrepancy within the Capabilities, Opportunities and Motivations framework (93): physical opportunity, educational attainment, and area deprivation are contributory factors in that they provide barriers to participation. Individuals may face financial barriers, digital poverty, have more pressing work or caring commitments, be in rural areas with less access to transport, or not have the inclination or trust in participating (33). Meanwhile, the risks of mortality for COVID-19 are cumulative. They include: being male, older, an ethnic minority, having an underlying health condition, working in a higher risk occupation and living in deprived areas (7). Those experiencing the highest levels of inequity have been more adversely affected by COVID-19

(7) yet only ten per cent of this review's total identified resources explicitly targeted individuals experiencing deprivation, digital poverty or low income, with the majority of socioeconomic outcomes assessing social isolation and loneliness. A number of resources were identified offering advice on housing, Universal Credit and other statutory services associated with lower incomes, but the review identified only fourteen community activities for people in deprivation categories, the majority of which were online art and nature resources and craft workshops, with three currently working on validated measurements (as yet unpublished), four using participant feedback, unnamed evaluation questionnaires, or reporting on strengths and challenges. It was therefore unclear whether community activities were efficacious within areas of deprivation. In addition, the target populations often overlapped between the three population areas, which demonstrates some of the associational effects of socioeconomic status on health and psychology . Given that vulnerable populations living in areas of deprivation appear to be more adversely affected by health inequity (9) and that community engagement can promote healthy psychological, physiological, social and behavioural responses $(33,94)$ there is an immediate value therefore in using community assets to engage with vulnerable groups. Community engagement can offer multiple avenues to support complex needs and has the potential to be particularly useful in promoting wellbeing within communities.

\section{Conclusions}

The aim of this review was to draw together a timely summary of how community activities have been utilised between March 2020 - January 2021 . The review examined how formal and informal community organisations, charities, community assets and mutual aid groups formed ad hoc services to support individuals. Some were formed with the specific aim of supporting vulnerable individuals through the pandemic, whilst others were aimed at supporting the social, physical and mental wellbeing of the community as a whole.

It is important within this field of study to understand the efficacy of such services, including short term and long term impacts. Existing research has shown that participation in arts, nature, music, cultural and physical activities is key to public health and wellbeing. This review found an abundance of resources and reports of cultural engagement amongst UK communities in response to the COVID-19 pandemic, with a diverse foci and design principles. 
Given the timescale, it is unlikely that there will be robust long term evidence of efficacy of these initiatives. There is a need therefore for further research, particularly on the efficacy of arts participation in addressing inequalities and supporting vulnerable populations.

\section{Declarations}

Ethics approval: Ethics approval was granted by the UCL Research Ethics Committee (4526.003).

Consent for publication: Not applicable. This manuscript does not contain data from individual participants. It does not include details, images or videos relating to an individual person.

Availability of data and materials: The datasets generated and analysed during the current study are available as supplementary material.

Competing Interests: The authors declare no competing interests.

Funding: This research was funded by AHRC/ UKRI (Ref: AH/V008595/1), UCL - Wellcome Institutional Strategic Support Fund (Ref: ISSF3/H17RCO/C5) and NIHR BRC Moorfields - UCL Therapeutic Acceleration Support (TAS) Fund (Ref: BRC3-305).

Author Contributions: RM, LT, ND, HC conceived and designed the analysis, contributed data analysis and wrote the paper. RM and LT collected the data.

Acknowledgements: We are grateful to all of the organisations who contributed to this research and to our collaborators and project partners for supplying information to support this study (including: University of Derby; Royal College of Music; Arts Council England; Culture, Health \& Wellbeing Alliance; NHS Personalised Care + National Academy of Social Prescribing; Natural England; Voluntary Arts; The Lived Experience Network). We are grateful to two students, Fran Green and Mayra Salazar Volkmann, for their contribution to this study.

\section{References}

1. Howarth M, Griffiths A, da Silva A, Green R. Social prescribing: a 'natural' community-based solution. Br J Community Nurs [Internet]. 2020 Jun 2;25(6):294-8. Available from: https://doi.org/10.12968/bjcn.2020.25.6.294

2. Luker KA, McHugh GA. Nurse prescribing from the community nurse's perspective. Int J Pharm Pract [Internet]. 2002 Dec 1;10(4):273-80. Available from: https://doi.org/10.1211/096176702776868433

3. Chatterjee H, Noble G. Museums, health and well-being. Ashgate Farnham; 2013.

4. Fancourt D, Finn S. What is the evidence on the role of the arts in improving health and well-being? A scoping review. 2020;

5. Henry H, Howarth ML. An overview of using an asset-based approach to nursing. Gen Pract Nurs. 2018;4(4):61-6.

6. Cyril S, Smith BJ, Possamai-Inesedy A, Renzaho AMN. Exploring the role of community engagement in improving the health of disadvantaged populations: a systematic review. Glob Health Action. 2015;8(1):29842.

7. Marmot M. Build Back Fairer: The COVID-19 Marmot Review. Pandemic, Socioecon Heal Inequalities Engl. 2020;

8. Bibby J, Everest G, Abbs I. Will COVID-19 be a watershed moment for health inequalities. Heal Found. 2020;

9. Marmot M. Health equity in England: the Marmot review 10 years on. Bmj. 2020;368.

10. Patel JA, Nielsen FBH, Badiani AA, Assi S, Unadkat VA, Patel B, et al. Poverty, inequality and COVID-19: the forgotten vulnerable. Public Health. 2020;183:110.

11. Propper C, Stoye G, Zaranko B. The wider impacts of the coronavirus pandemic on the NHS. Fisc Stud. 2020;41(2):345-56.

12. Johnson S, Dalton-Locke C, San Juan NV, Foye U, Oram S, Papamichail A, et al. Impact on mental health care and on mental health service users of the COVID-19 pandemic: a mixed methods survey of UK mental health care staff. Soc Psychiatry Psychiatr Epidemiol. 2021;56(1):25-37.

13. McKenzie G, Adams B. A country comparison of place-based activity response to COVID-19 policies. Appl Geogr. 2020;125:102363.

14. Culture Health and Wellbeing Alliance. How creativity and culture are supporting shielding and vulnerable people at home during Covid-19. 2020.

15. Khangura S, Konnyu K, Cushman R, Grimshaw J, Moher D. Evidence summaries: the evolution of a rapid review approach. Syst Rev. 2012;1(1):1-9.

16. Office for National Statistics. A summary of social relationships and social support for vulnerable groups [Internet]. 2021. Available from: https://www.ons.gov.uk/peoplepopulationandcommunity/wellbeing/articles/coronavirusandsocialrelationshipsandsupportforvulnerablegroups/202004-02\#glossary

17. Culture Health and Wellbeing Alliance. Culture Health and Wellbeing Alliance [Internet]. 2021. Available from:

https://www.culturehealthandwellbeing.org.uk

18. Arts Council England. Arts Council England [Internet]. 2021. Available from: https://www.artscouncil.org.uk/funding

19. Natural England. Natural England. 2021.

20. March Network. The MARCH Network [Internet]. 2021. Available from: https://www.marchnetwork.org

21. GOV.UK. GOV.UK. 2021.

22. Office for National Statistics. Office for National Statistics. 2021.

23. Daykin N. Arts for Health and Wellbeing. An Evaluation Framework. 2016; 
24. Karlsson LE, Takahashi R. ANNEX 4. SELECTION OF TOOLS FOR APPRAISING EVIDENCE. In: A Resource for Developing an Evidence Synthesis Report for Policy-Making [Internet]. WHO Regional Office for Europe; 2017.

25. Shea BJ, Reeves BC, Wells G, Thuku M, Hamel C, Moran J, et al. AMSTAR 2: a critical appraisal tool for systematic reviews that include randomised or non-randomised studies of healthcare interventions, or both. bmj. 2017;358.

26. Maxwell L, Santesso N, Tugwell PS, Wells GA, Judd M, Buchbinder R. Method guidelines for Cochrane Musculoskeletal Group systematic reviews. J Rheumatol. 2006;33(11):2304-11.

27. Richardson WS, Wilson MC, Nishikawa J, Hayward RS. The well-built clinical question: a key to evidence-based decisions. Acp j club. 1995;123(3):A12-3.

28. Pierce M, Hope H, Ford T, Hatch S, Hotopf M, John A, et al. Mental health before and during the COVID-19 pandemic: a longitudinal probability sample survey of the UK population. The Lancet Psychiatry. 2020;7(10):883-92.

29. Fluharty M, Fancourt D. How have people been coping during the COVID-19 pandemic? Patterns and predictors of coping strategies amongst 26,580 UK adults. 2020;

30. Samaroudi M, Echavarria KR, Perry L. Heritage in lockdown: digital provision of memory institutions in the UK and US of America during the COVID-19 pandemic. Museum Manag Curatorsh. 2020;35(4):337-61.

31. von Humboldt S, Mendoza-Ruvalcaba NM, Arias-Merino ED, Costa A, Cabras E, Low G, et al. Smart technology and the meaning in life of older adults during the Covid-19 public health emergency period: a cross-cultural qualitative study. Int Rev Psychiatry [Internet]. 2020 Nov 16;32(7-8):713-22. Available from: https://doi.org/10.1080/09540261.2020.1810643

32. Bu F, Steptoe A, Mak HW, Fancourt D. Time-use and mental health during the COVID-19 pandemic: a panel analysis of 55,204 adults followed across 11 weeks of lockdown in the UK. medRxiv. 2020;

33. Fancourt D, Baxter L. Differential participation in community cultural activities amongst those with poor mental health: Analyses of the UK Taking Part Survey. Soc Sci Med. 2020;261:113221.

34. Vuillier L, May L, Greville-Harris M, Surman R, Moseley RL. The impact of the COVID-19 pandemic on individuals with eating disorders: the role of emotion regulation and exploration of online treatment experiences. J Eat Disord. 2020;9(1):1-18.

35. Brown S, Opitz M-C, Peebles Al, Sharpe H, Duffy F, Newman E. A qualitative exploration of the impact of COVID-19 on individuals with eating disorders in the UK. Appetite. 2021;156:104977.

36. Schlegl S, Maier J, Meule A, Voderholzer U. Eating disorders in times of the COVID-19 pandemic-Results from an online survey of patients with anorexia nervosa. Int J Eat Disord. 2020;53(11):1791-800.

37. Weinstein N, Nguyen T-V. Motivation and preference in isolation: a test of their different influences on responses to self-isolation during the COVID-19 outbreak. R Soc Open Sci. 2020;7(5):200458.

38. Ratschen E, Shoesmith E, Shahab L, Silva K, Kale D, Toner P, et al. Human-animal relationships and interactions during the Covid-19 lockdown phase in the UK: Investigating links with mental health and loneliness. PLoS One. 2020;15(9):e0239397.

39. Fancourt D, Bu F, Mak HW, Steptoe A. COVID-19 social study. Results release. 2020;15.

40. Akulwar-Tajane I, Parmar K, Naik P, Shah A. Rethinking Screen Time during COVID-19: Impact on Psychological Well-Being in Physiotherapy Students. Int J Clin Exp Med Res. 2020;Sep 24(4):201-16.

41. Institute of Fiscal Studies. The mental health effects of the first two months of lockdown and social distancing during the Covid-19 pandemic in the UK [Internet]. 2020. Available from: https://www.ifs.org.uk/publications/14874

42. Mental Health Foundation. Coping with the pandemic: New mental health research reveals how UK adults are managing stress. 2020.

43. Lades LK, Laffan K, Daly M, Delaney L. Daily emotional well-being during the COVID-19 pandemic. Br J Health Psychol. 2020;25(4):902-11.

44. Office for National Statistics. Coronavirus and depression in adults, Great Britain: June 2020 [Internet]. 2020. Available from: https://www.ons.gov.uk/peoplepopulationandcommunity/wellbeing/articles/coronavirusanddepressioninadultsgreatbritain/june2020

45. Wellcome Mental Health. Covid Living Wrap up Report [Internet]. 2020. Available from: https://www.rhs.org.uk/advice/health-andwellbeing/articles/Lockdown-lowdown

46. Wellcome Collection. Collective Resillience: How we've protected our mental health during Covid-19. [Internet]. 2020. Available from: https://cms.wellcome.org/sites/default/files/collective-resilience-how-protected-mental-health-during-covid-19.pdf

47. The Royal Horticultural Society. Get the Gardening Low-down on Lock-down. 2020; Available from: https://www.rhs.org.uk/advice/health-andwellbeing/articles/Lockdown-lowdown

48. The National Trust. UK values nature more as a result of lockdown, according to summer solstice poll [Internet]. 2020. Available from: UK values nature more as a result of lockdown, according to summer solstice poll

49. RSPB. Recovering Together: A Report Of Public Opinion On The Role And Importance Of Nature During And In Our Recovery From The Coronavirus Crisis In England. 2020.

50. Thrive. Gardening helps mental health during Covid-19. 2020.

51. 56 Degree Insight. COVID-19 Impacts: Engaging with the outdoors during and beyond lockdown [Internet]. 2020. Available from: https://www.56degreeinsight.com/covid19-engaging-with-the-outdoors

52. The Crafts Council. The Market for Craft: Commissioned by the Crafts Council and Partners Report. 2020.

Page 12/15 
53. Niedzwiedz CL, Green M, Benzeval M, Campbell DD, Craig P, Demou E, et al. Mental health and health behaviours before and during the COVID-19 lockdown: Longitudinal analyses of the UK Household Longitudinal Study. medRxiv. 2020;

54. Fischer R, Bortolini T, Karl JA, Zilberberg M, Robinson K, Rabelo A, et al. Rapid review and meta-meta-analysis of self-guided interventions to address anxiety, depression, and stress during COVID-19 social distancing. Front Psychol. 2020;11.

55. Karwowski M, Zielińska A, Jankowska DM, Strutyńska E, Omelańczuk I, Lebuda I. Creative lockdown? A daily diary study of creative activity during pandemics. Front Psychol. 2021;12:23.

56. The Conservation Volunteers. Enabling the potential of social prescribing. 2020.

57. Blake H, Yildirim M, Wood B, Knowles S, Mancini H, Coyne E, et al. COVID-Well: Evaluation of the implementation of Supported Wellbeing Centres for hospital employees during the COVID-19 pandemic. Int J Environ Res Public Health. 2020;17(24):9401.

58. Y Lab. HARP COVID-10 Sprint Challenge. 2020.

59. Wolf K, Reinhardt J, Funk M. Virtual exhibitions: what do we win and what do we lose? Electron Vis Arts. 2018;79-86.

60. Hacker J, vom Brocke J, Handali J, Otto M, Schneider J. Virtually in this together - how web-conferencing systems enabled a new virtual togetherness during the COVID-19 crisis. Eur J Inf Syst [Internet]. 2020 Sep 2;29(5):563-84. Available from: https://doi.org/10.1080/0960085X.2020.1814680

61. Faulkner J, O'Brien WJ, McGrane B, Wadsworth D, Batten J, Askew CD, et al. Physical activity, mental health and well-being of adults during initial COVID-19 containment strategies: A multi-country cross-sectional analysis. J Sci Med Sport. 2021;24(4):320-6.

62. Jacob L, Tully MA, Barnett Y, Lopez-Sanchez GF, Butler L, Schuch F, et al. The relationship between physical activity and mental health in a sample of the UK public: A cross-sectional study during the implementation of COVID-19 social distancing measures. Ment Health Phys Act. 2020;19:100345.

63. Nigro E, Polito R, Alfieri A, Mancini A, Imperlini E, Elce A, et al. Molecular mechanisms involved in the positive effects of physical activity on coping with COVID-19. Eur J Appl Physiol. 2020;1-14.

64. McCall M, Heneghan C, Nunn D. Does physical exercise prevent or treat acute respiratory infection (ARI)?. Report. Centre for Evidence Based Medicine. Oxford. [Internet]. 2020. Available from: https://www.cebm.net/covid-19/does-physical-exercise-prevent-or-treat-acute-respiratory-infection-ari/

65. Robinson E, Boyland E, Chisholm A, Harrold J, Maloney NG, Marty L, et al. Obesity, eating behavior and physical activity during COVID-19 lockdown: A study of UK adults. Appetite. 2021;156:104853.

66. What Works Centre for Wellbeing. Virtual Choirs and Wellbeing. 2020.

67. Buckley R, Westaway D. Mental health rescue effects of women's outdoor tourism: A role in COVID-19 recovery. Ann Tour Res. 2020;85:103041.

68. Johannes N, M V, AK P. Video game play is positively correlated with well-being. R Soc open Sci. 2020;17(8).

69. Baracsi Z. Coronavirus Kindnes Phenomenon: Trends of Social Flow of Creativity during the First 27 Days of Social Distancing in the COVID-19 Pandemic in the UK. pHD Preliminary Research. [Internet]. 2020. Available from: http://www.wiseninggate.uk/documents/covid.pdf

70. Kriz WC. Gaming in the Time of COVID-19. Simul Gaming [Internet]. 2020 Jul 14;51(4):403-10. Available from: https://doi.org/10.1177/1046878120931602

71. Townsend L. The professional wild food community and Covid-19: The use of online platforms in supporting people to access alternative food sources. Local Dev Soc. 2020;1-6.

72. Rousseau S, Deschacht N. Public awareness of nature and the environment during the COVID-19 crisis. Environ Resour Econ. 2020;76(4):1149-59.

73. Zabini F, Albanese L, Becheri FR, Gavazzi G, Giganti F, Giovanelli F, et al. Comparative study of the restorative effects of forest and urban videos during COVID-19 lockdown: Intrinsic and benchmark values. Int J Environ Res Public Health. 2020;17(21):8011.

74. Giordano F, Scarlata E, Baroni M, Gentile E, Puntillo F, Brienza N, et al. Receptive music therapy to reduce stress and improve wellbeing in Italian clinical staff involved in COVID-19 pandemic: A preliminary study. Arts Psychother. 2020;70:101688.

75. Viana R, de Lira C. Exergames as coping strategies for anxiety disorders during the COVID-19 quarantine period. Games Heal journal. 2020;Jun 1(3):147-9.

76. Gilbert B. Examining the motivations and emotions linked to the formation of a Voluntary sewing group formed in response to Covid-19 'Tamworth Volunteers - Sewing for NHS and Healthcare Workers. University of Worchester. 2020.

77. Choi M, Tessler H, Kao G. Arts and crafts as an educational strategy and coping mechanism for Republic of Korea and United States parents during the COVID-19 pandemic. Int Rev Educ [Internet]. 2020;66(5):715-35. Available from: https://doi.org/10.1007/s11159-020-09865-8

78. University of Cumbria. Connection with Nature in the UK during the COVID-19 Lockdown. 2020.

79. Ugolini F, Massetti L, Calaza-Martínez P, Cariñanos P, Dobbs C, Ostoić SK, et al. Effects of the COVID-19 pandemic on the use and perceptions of urban green space: An international exploratory study. Urban For urban Green. 2020;56:126888.

80. Rogers NT, Waterlow NR, Brindle H, Enria L, Eggo RM, Lees S. Behavioral change towards reduced intensity physical activity is disproportionately prevalent among adults with serious health issues or self-perception of high risk during the UK COVID-19 lockdown. Front public Heal. $2020 ; 8$.

81. Rowley N, Shore C, Buckley B, Hesketh K. Adapt or Perish: Exercise referral schemes' operational changes during the Covid-19 pandemic. Sport Oct. 2020;2.

82. McCarthy H, Potts HWW, Fisher A. Physical Activity Behavior Before, During, and After COVID-19 Restrictions: Longitudinal Smartphone-Tracking Study of Adults in the United Kingdom. J Med Internet Res. 2021;23(2):e23701.

83. Sport England. COVID-19 Briefing: Exploring the attitudes and behaviours in England during the COVID 19 Pandemic. 2020. 
84. Sharma V, Smith A, Khan M. The relationship between duration of labour, time of delivery, and puerperal psychosis. J Affect Disord. 2004;83(23):215-20.

85. Heyang T, Martin R. A reimagined world: international tertiary dance education in light of COVID-19. Res Danc Educ. 2020;1-15.

86. Philip KEJ, Lewis A, Jeffery E, Buttery S, Cave P, Cristiano D, et al. Moving singing for lung health online in response to COVID-19: experience from a randomised controlled trial. BMJ open Respir Res. 2020;7(1):e000737.

87. Mürbe D, Fleischer M, Lange J, Rotheudt H, Kriegel M. Aerosol emission is increased in professional singing. 2020;

88. Giebel C, Pulford D, Cooper C, Lord K, Shenton J, Cannon J, et al. COVID-19-related social support service closures and mental well-being in older adults and those affected by dementia: a UK longitudinal survey. BMJ Open. 2021;11(1):e045889.

89. Lee S, O'Neill D, Moss H. Promoting well-being among people with early-stage dementia and their family carers through community-based group singing: a phenomenological study. Arts Health. 2020;1-17.

90. Roberts K. Locked down leisure in Britain. Leis Stud. 2020;39(5):617-28.

91. Mak HW, Fluharty M, Fancourt D. Predictors and Impact of Arts Engagement During the COVID-19 Pandemic: Analyses of Data From 19,384 Adults in the COVID-19 Social Study [Internet]. Vol. 12, Frontiers in Psychology. 2021. p. 1335. Available from:

https://www.frontiersin.org/article/10.3389/fpsyg.2021.626263

92. Collective Encounters. Delivering Participatory Theatre during the Pandemic: What's working? 2020.

93. Michie S, Van Stralen MM, West R. The behaviour change wheel: a new method for characterising and designing behaviour change interventions. Implement Sci. 2011;6(1):1-12.

94. Randler C, Tryjanowski P, Jokimäki J, Kaisanlahti-Jokimäki M-L, Staller N. SARS-CoV2 (COVID-19) Pandemic Lockdown Influences Nature-Based Recreational Activity: The Case of Birders. Int J Environ Res Public Health. 2020;17(19):7310.

\section{Figures}

PRISMA 2020 flow diagram for updated systematic reviews which included searches of databases, registers and other sources

Identification of resources via databases, registers and other methods
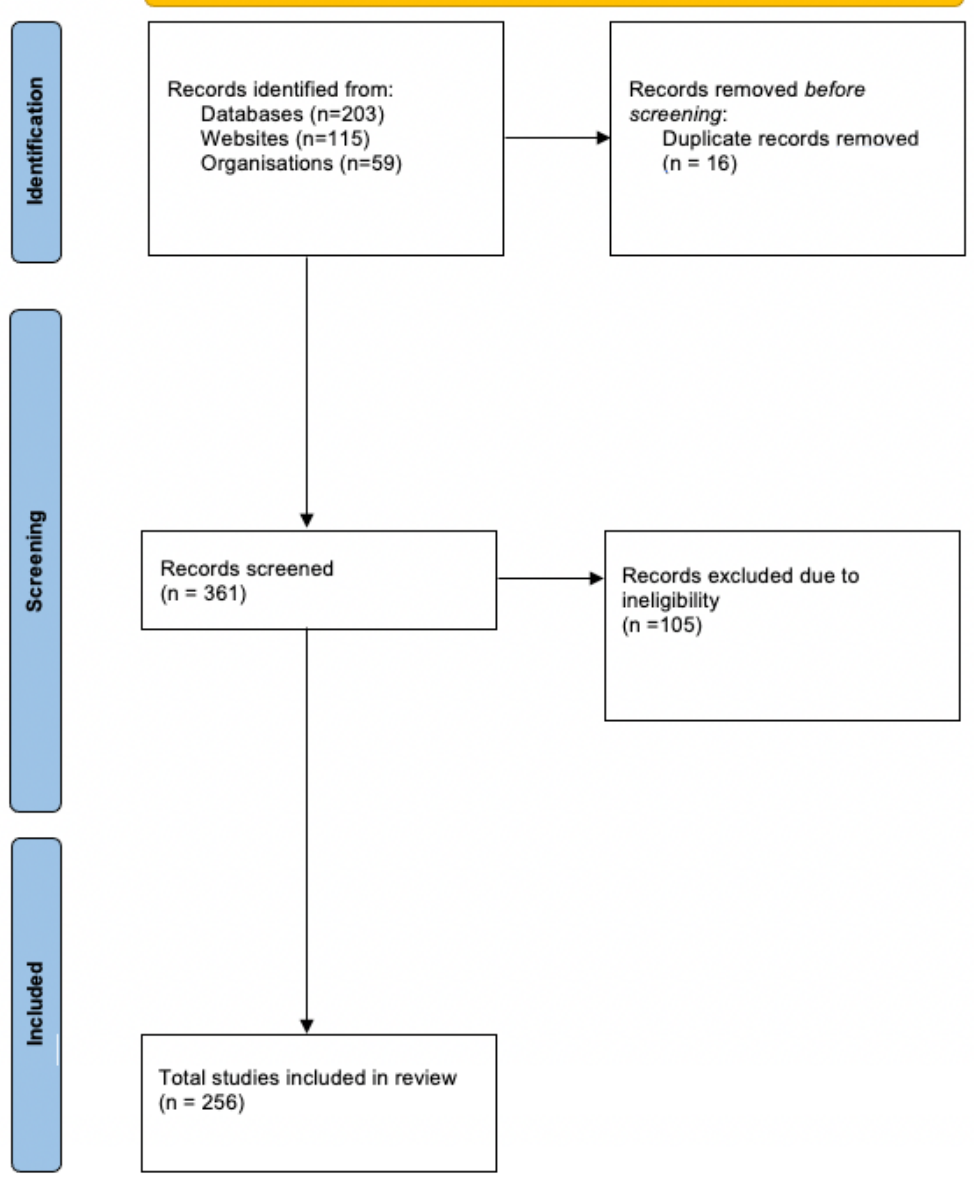

Records excluded due to ineligibility

Figure 1 
PRISMA Flow Diagram of searches of databases, registers and other sources

\section{Supplementary Files}

This is a list of supplementary files associated with this preprint. Click to download.

- AdditionalFile1.xlsx

- Appendixl.docx 